\title{
LOS BALDECITOS (SAN JUAN, ARGENTINA) COMO PORTAL DEL PARQUE PROVINCIAL ISCHIGUALASTO (PATRIMONIO DE LA HUMANIDAD): PUESTA EN VALOR DEL PATRIMONIO CULTURAL TANGIBLE E INTANGIBLE
}

\section{LOS BALDECITOS (SAN JUAN, ARGENTINA) AS THE PORTAL OF THE ISCHIGUALASTO PROVINCIAL PARK (WORLD HERITAGE SITE): ENHANCEMENT OF THE TANGIBLE AND INTANGIBLE CULTURAL HERITAGE}

\author{
Yamila V. Andrada \\ CONICET-FAUD, Universidad Nacional de San Juan, Argentina
}

Pedro O. Narváez

Universidad Nacional de San Juan, Argentina

Claudia M. Campos

Instituto Argentino de Investigaciones de las Zonas Áridas, CONICETU, Argentina

\section{RESUMEN}

Se analiza el potencial turístico, con relación al patrimonio cultural tangible e intangible, de la localidad Los Baldecitos, aledaña al Parque Provincial Ischigualasto (PPI). Para ello, se inventariaron los puntos de interés; se rescataron aspectos del patrimonio intangible; se relevó información de la planta turística e infraestructura; se indagó acerca del interés de turistas y pobladores por iniciativas en la localidad; y se analizaron fortalezas, oportunidades, debilidades y amenazas, considerando la información obtenida en el escenario de la actual pandemia. Los Baldecitos cuenta con recursos para realizar una oferta interesante. Los desafíos se relacionan con la falta de mantenimiento de los puntos de interés, la falta de soporte desde organizaciones privadas y estatales, y el impacto de la pandemia COVID-19. El PPI es el área protegida más visitada de la provincia y con mucha promoción a nivel nacional, pero el 'efecto derrame' de los beneficios no llega a esta localidad. Es necesario que los pobladores tomen la decisión de poner en movimiento proyectos; que los beneficios que emanan de la estrecha relación con el parque y de la nueva tendencia mundial hacia la recuperación del turismo por medio de la sustentabilidad, se concreten con subsidios y soporte técnico para las iniciativas de los pobladores.

Palabras clave: área protegida, bienes patrimoniales, conservación, pandemia COVID-19, patrimonio cultural, turismo sustentable.

Este es un artículo Open Access bajo la licencia Creative Commons AtribuciónNoComercial-Compartirlgual 4.0

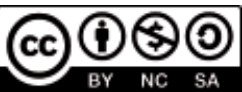




\begin{abstract}
The tourism potential is analyzed, in relation to the tangible and intangible cultural heritage, of Los Baldecitos locality, adjacent to the Ischigualasto Provincial Park. To do this, the points of interest were inventoried, aspects of the intangible heritage were rescued, information on the tourist acommodations and infrastructure was collected, an inquiry was made about the interest of tourists and residents for initiatives in the locality, and strengths, opportunities, weaknesses, strengths and threats were analyzed, considering the information obtained in the scenario of the current pandemic. Los Baldecitos has the resources to make an interesting offer. The challenges are related to the lack of maintenance of the points of interest, the lack of support from private and state organizations, and the impact of the COVID-19 pandemic. The Ischigualasto Provincial Park is the most visited protected area in the province and with much promotion at the national level, but the «spillover effect» of the benefits does not reach Los Baldecitos. It is necessary that the residents make the decision to put projects in motion and that the benefits that emanate from the close relationship with the park and the new global trend towards the recovery of tourism through sustainability, are materialized with subsidies and technical support for the initiatives of the villagers.
\end{abstract}

Keywords: protected area, heritage assets, conservation, pandemic, COVID-19, cultural heritage, sustainable tourism.

\title{
Introducción
}

Las áreas naturales protegidas pueden ser vistas como elementos del paisaje socioecológico que participan de las dinámicas sociales, económicas y ecológicas a lo largo de diferentes escalas espaciales y niveles institucionales (Padt et al., 2014). Con su particular forma de manejo, orientada a la conservación de los bienes naturales, las áreas protegidas producen 'efectos de derrame', es decir, impactos sobre las áreas adyacentes, que son ampliamente estudiados desde la ecología (Blitzer et al., 2012) y, que recientemente, comenzaron a considerarse desde el punto de vista socioeconómico (Ament y Cumming, 2016). Por ejemplo, el turismo sostenible en áreas protegidas puede contribuir a la conservación de la naturaleza mediante la divulgación y educación que esté dirigida a los visitantes; generación de recursos económicos que pueden volver hacia la conservación y la generación de posibilidades de trabajo para las comunidades vecinas (Fuentes, 1995). De esta forma, el efecto derrame del turismo sostenible en las áreas protegidas se manifiesta en la creación de alternativas e incentivos que habilitan el desarrollo social y económico, local y regional.

La creación de áreas protegidas constituye una estrategia fundamental para la conservación a largo plazo de la diversidad biológica y cultural, proporcionando bienes y servicios ecosistémicos esenciales para la sociedad y la vida en general. Entre los beneficios y valores que brindan, se encuentra el permitir el desarrollo de actividades turísticas y recreativas sustentables, que aprovechan las condiciones naturales y culturales de estas áreas -potencial turístico- según Santos-Pavón et al. (2016). Las condiciones culturales cobran importancia mediante los bienes patrimoniales, los cuales pueden considerarse como la heredad social y colectiva de un grupo humano (pueblo o nación), cualquiera sea la naturaleza de esa heredad, constituidos en bienes no enajenables, que nadie debe lesionar (Papparelli et al., 2003). Los bienes patrimoniales pueden clasificarse en bienes de carácter tangible 
e intangible. En el primer grupo se han incorporado aquellos valores materiales o culturales con características y tipologías fáciles de definir y cuantificar, que reportan interés sustancial y significan un aporte relevante para el desarrollo de la cultura de los pueblos. Los bienes intangibles, en cambio, son los aspectos más sutiles y complejos del patrimonio, posibles de identificar cualitativamente, pero de muy difícil cuantificación; integran el acervo cultural de un pueblo y puede ser transmitido de generación en generación (Papparelli et al., 2003). Por medio del turismo, el patrimonio se puede activar, valorizar y resignificar, e incluso se llega a promover la patrimonialización de elementos que antes no habían sido considerados. El turismo, entonces, además de concienciar sobre la importancia de la conservación del patrimonio, genera el movimiento que ayuda a obtener recursos económicos para su preservación (Diekmann y Smith, 2003).

El turismo sustentable puede ser considerado un modelo de desarrollo económico diseñado para mejorar la calidad de vida de la población local, proveer de mayor experiencia al visitante, mantener la calidad del medio ambiente, alcanzar los mayores niveles de rentabilidad económica de la actividad turística para los residentes locales y asegurar beneficios por parte de los empresarios turísticos (Sancho, 1998). La actividad turística tiene potencial para promover el crecimiento económico y la inversión a nivel local, lo cual a su vez se traduce en oportunidades de empleo, distribución de rentas y en impulso para otras actividades económicas en las localidades receptoras (Morillo, 2011). Desde esta perspectiva, el turismo puede y debe convertirse en un aliado del ambiente en el que se desarrolla, en una fuerza económica y política de apoyo que asegure la conservación de los espacios y medios que utiliza (Secretaría de Ambiente y Desarrollo Sustentable de la Nación, 2008). En este contexto, la prevención de impactos negativos generados por el turismo sobre la diversidad biológica y cultural es un tema crítico (Fennel y Ebert, 2004). No obstante, planeado y manejado adecuadamente, el turismo sustentable contribuye a la conservación biocultural (Acevedo, 2006).

El turismo sustentable podría constituirse en una alternativa crucial durante la época pospandemia que se avecina, siempre en el marco de las recomendaciones que emite el Comité Mundial de Crisis para el Turismo, establecido por la OMT como respuesta a la crisis de la COVID-19. Desde la OMT se piensa que, ahora que los gobiernos y el sector privado se adentran en el camino de la recuperación, es el momento de seguir avanzando hacia un modelo de turismo más sustentable en lo económico, social y ambiental (como se citó en One Planet Sustainable Tourism Programme, 2020). Un turismo sustentable con una fuerte orientación hacia el turismo interno, planificado y gestionado con responsabilidad, será de gran relevancia para ayudar a la recuperación de las economías regionales, por su capacidad de contribuir a la creación de empleo, promover una integración social inclusiva, proteger el patrimonio natural y cultural, y conservar la biodiversidad.

El presente trabajo tiene como objetivo general analizar el potencial turístico, en cuanto a su patrimonio cultural tangible e intangible, de la localidad Los Baldecitos aledaña al Parque Provincial Ischigualasto. Para ello, se proponen los siguientes objetivos específicos: 1. Identificar e inventariar los puntos de interés del patrimonio cultural tangible con mayor potencial para convertirse en atractivos turísticos; 2. Rescatar aspectos del patrimonio cultural intangible que enriquezcan los atractivos turísticos; 3. Relevar información de la planta turística, infraestructura y superestructura; 4. Indagar el interés de turistas y pobladores por el desarrollo turístico de la localidad; 5. Realizar un análisis de fortalezas, oportunidades, debilidades y amenazas (FODA), considerando la información obtenida en el marco del actual brote mundial de COVID-19 y pensando en la recuperación del 
turismo durante la pospandemia. Se espera que estos resultados puedan constituirse en una herramienta para el desarrollo de futuros proyectos de gestión del área de influencia del PPI.

\section{Materiales y métodos}

\section{Sitio de estudio}

El Parque Provincial Ischigualasto (PPI), ubicado en el departamento Valle Fértil, en la provincia de San Juan ( $29^{\circ} 55^{\prime} \mathrm{S}, 68^{\circ} 05^{\prime} \mathrm{O}$ ), constituye un sitio paleontológico de importante valor (Figura 1). Esto es así debido a que conserva el único lugar en el mundo que posee la secuencia completa de sedimentos continentales del período Triásico, con un abundante registro fósil, que revela la evolución de la vida de los vertebrados y la naturaleza de los paleoambientes. Esta riqueza paleontológica motivó la creación del área protegida en el año 1971. Posteriormente, en el año 2000, el PPI fue declarado Patrimonio de la Humanidad por UNESCO, junto con el Parque Nacional Talampaya. Las diversas geoformas que resaltan en el paisaje le dieron el nombre de Valle de la Luna. Desde el punto de vista arqueológico se destacan sitios con representaciones grabadas de marcas de ganado que son testimonio de actividades de arreo de vacunos que se desarrollaron en la región desde épocas coloniales hasta fines del siglo XIX y las primeras décadas del siglo XX (Michieli, 1994; Podestá et al., 2011; Rolandi et al., 2003, 2008).

\section{Figura 1}

Ubicación de la localidad Los Baldecitos, próxima al Parque Provincial Ischigualasto (San Juan, Argentina)

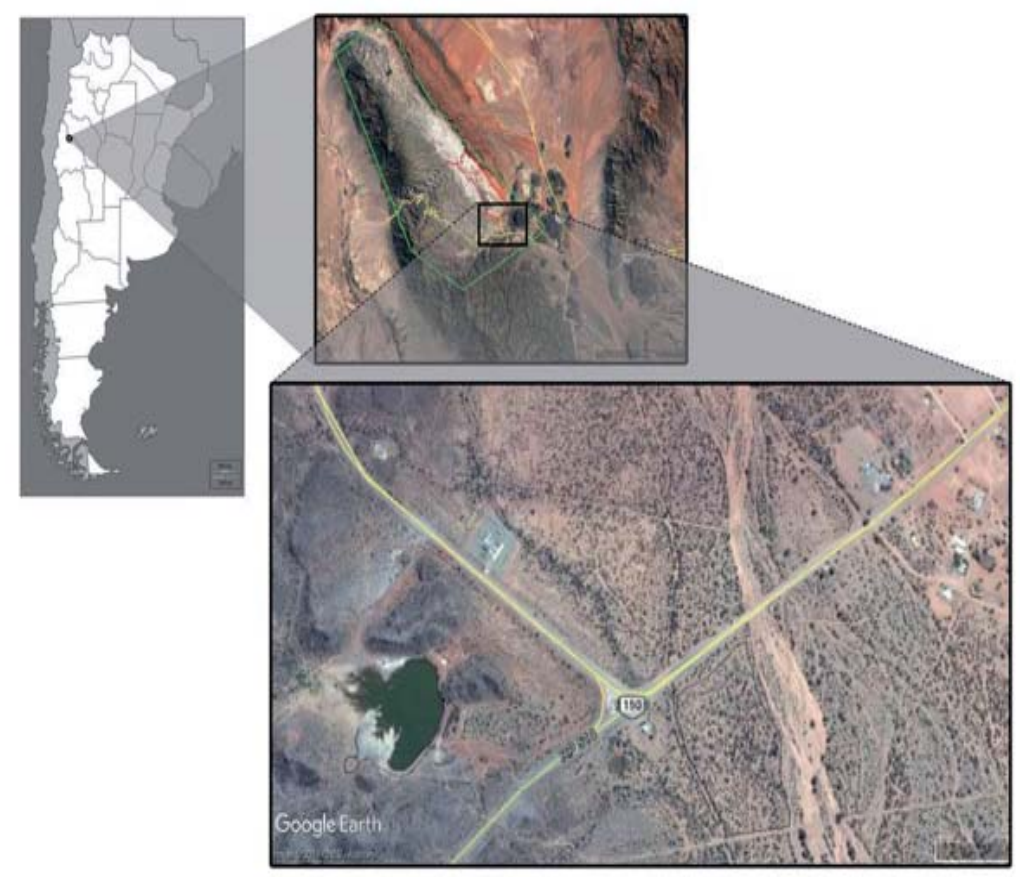

Nota. Dentro de las imágenes satelitales, la línea verde muestra los límites del PPI, la línea roja destaca el circuito turístico dentro del parque. En amarillo se visualizan las principales rutas. 
En la zona de influencia del PPI se encuentra la localidad de Los Baldecitos, en el extremo noreste de la Provincia de San Juan. Es una localidad con pocos habitantes (aproximadamente 60 personas) donde prevalece el modo de vida rural. Su nombre deriva de la palabra 'balde» que refiere al recipiente con el que se extraía manualmente el agua mediante la utilización de sogas y poleas de las perforaciones similares a aljibes, construidas para acceder a las napas de agua subterránea. Desde 1930 hasta aproximadamente 1960, los pobladores de la zona trabajaron en las minas de mica y cuarzo, algunas de las cuales aún siguen en actividad. También fueron guías y acompañantes de los paleontólogos que realizaban sus expediciones. La actividad, que persiste hasta la actualidad, es la cría extensiva de ganado por unas pocas familias. Por cercanía, y punto de tránsito para dirigirse al PPI, se dedican a la prestación de servicios turísticos en pequeña escala. Su principal vía de comunicación es la Ruta Nacional n. ${ }^{\circ}$ 150, que forma parte del corredor bioceánico, que une Coquimbo en Chile y Porto Alegre en Brasil.

\section{Diseño del trabajo}

Para identificar y realizar un inventario de los puntos de interés del patrimonio cultural (objetivo 1) se obtuvo información a partir de entrevistas -en profundidad- con informantes claves: cinco pobladores mayores de edad y con muchos años de residencia en la localidad, los cuales aportaron además información sobre el patrimonio cultural intangible (leyendas locales, historia del pueblo, etc.) (objetivo 2). Contando con la guía de los informantes, se visitaron los sitios de interés para hacer un relevamiento fotográfico y georeferenciar los puntos. La información brindada por los pobladores se complementó con la obtenida a partir de una búsqueda bibliográfica de publicaciones científicas e informes técnicos. Para las entrevistas se siguió el Código de Ética de la Sociedad Latinoamericana de Etnobiología (SOLAE, 2016). Los informantes son identificados en el trabajo con seudónimos, respetando su deseo de anonimato.

Para relevar información de la planta turística (objetivo 3) se visitaron los distintos establecimientos y se solicitaron los datos a sus propietarios; se realizaron encuestas al azar a turistas adultos que visitaron el PPI $(\mathrm{N}=32)$ y a pobladores $(\mathrm{N}=8)$ con el fin de conocer el interés en el desarrollo de propuestas turísticas para la localidad (objetivo 4).

Finalmente, con los datos obtenidos, se realizó el análisis de fortalezas, oportunidades, debilidades y amenazas (FODA) (objetivo 4), considerando la siguiente escala para el grado de incidencia: escasa (1), baja (2), media (3), alta (4) y muy alta (5). Se calcularon las sumas y promedios de los ítems para estimar fortalezas, oportunidades, debilidades y amenazas, así como potencialidades, limitaciones y desafíos.

\section{Resultados}

\section{Puntos de interés del patrimonio cultural}

Los puntos de interés identificados se relacionan estrechamente con asentamientos de los primeros pobladores en el área a fines del año 1800. Muchas de las construcciones siguen utilizándose en la actualidad, mientras que otras muestran el impacto del paso del tiempo y las alteraciones producidas por el empleo de materiales y 
tecnologías industrializadas. En este ambiente árido, con precipitaciones anuales de apenas $200 \mathrm{~mm}$, la limitante más importante fue la obtención de agua. Entonces, las familias se establecieron en sitios donde podían obtener agua con el sistema de los 'pozos baldes' y allí construyeron sus casas utilizando los materiales de la zona (tierra, piedras, madera). Las viviendas están acompañadas de cercos, corrales, cobertizos, reservas de agua, el horno para cocinar pan, las 'ramadas' y los fogones. Las edificaciones más antiguas poseen características en cuanto a implantación y orientación, agrupamiento de locales, patios, tamaño de habitaciones y aspectos constructivos que las identifican con las formas tradicionales locales y regionales de habitar (Rolandi et al., 2007). Existen diferentes tipos de técnicas constructivas: piedra y piedra con barro en viviendas más antiguas y actualmente sin uso; adobe con barro, piedra con barro, palo a pique y entramados en viviendas y su equipamiento doméstico en casas del pueblo. En construcciones de uso actual (como la iglesia y la escuela nueva) se combinan materiales y técnicas vernáculas con técnicas mixtas y el uso de materiales industriales como ladrillo común cocido, hormigón armado, ladrillo hueco, cemento, cal, chapa de cinc, techos metálicos y carpinterías de chapa (Rolandi et al., 2003).

El almacenamiento del agua para los animales domésticos (ovejas, cabras, vacas) de toda la población se realiza en 'represas', que son excavaciones de unos $50 \mathrm{~m}$ de diámetro que se llenan de agua. Algunos sitios bajos e inundables (bañados) ubicados en pequeños valles fueron utilizados hasta hace pocos años para el cultivo de maíz, zapallo, etc., en parcelas que pertenecían a las diferentes familias.

\section{Inventario de los puntos de interés del patrimonio cultural de Los Baldecitos (San Juan, Argentina)}

1. Casa de Don Victorino Herrera (Fig. 2). Es una de las casas más llamativas de la zona, propiedad de Victorino Herrera y su familia. Fue construida aproximadamente en el año 1940, con piedra, barro y mica. Algunas de sus paredes fueron construidas de palo a pique, con puntales de algarrobos muy gruesos (Rotondaro et al., 2007). Los techos tienen vigas de algarrobo, con un relleno de coirón, una gramínea del género Stipa, que se trozaba y mezclaba con barro. Se cruzaban ramas de puspús (Zuccagnia punctata), un arbusto resinoso. Las columnas, llamadas horcones, son de palos de algarrobo. El arco de entrada y los techos están ornamentados con esculturas de madera tallada que representan animales. Victorino Herrera fue un pionero que conocía bien la región. Fue quien guió a los primeros paleontólogos que visitaron el parque en busca de restos fósiles. El primer dinosaurio de Ischigualasto se encontró en el año 1958 y en honor a él se lo nombró Herrerasaurus ischigualastensis.

2. Casa de don Benedicto de los Ángeles Herrera (Fig. 3). Casa de uno de los primeros pobladores, que la construyó en el año 1908. Es de gran tamaño y sus habitaciones se abren hacia las galerías que rodean un patio central. Las paredes son de adobe tradicional con juntas de barro, algunas son de piedra redondeada elegidas en las cercanías, con mezcla de barro (Rotondaro, 2007).

3. Casa de la infancia de doña Alba (Fig. 4). Perteneció a la familia Ontiveros, una de las dos familias más antiguas de la localidad. Fue construida con adobe tradicional y con juntas de barro. Las columnas u horcones son palos de algarrobo. 


\section{Figura 2}

Casa de don Victorino Herrera

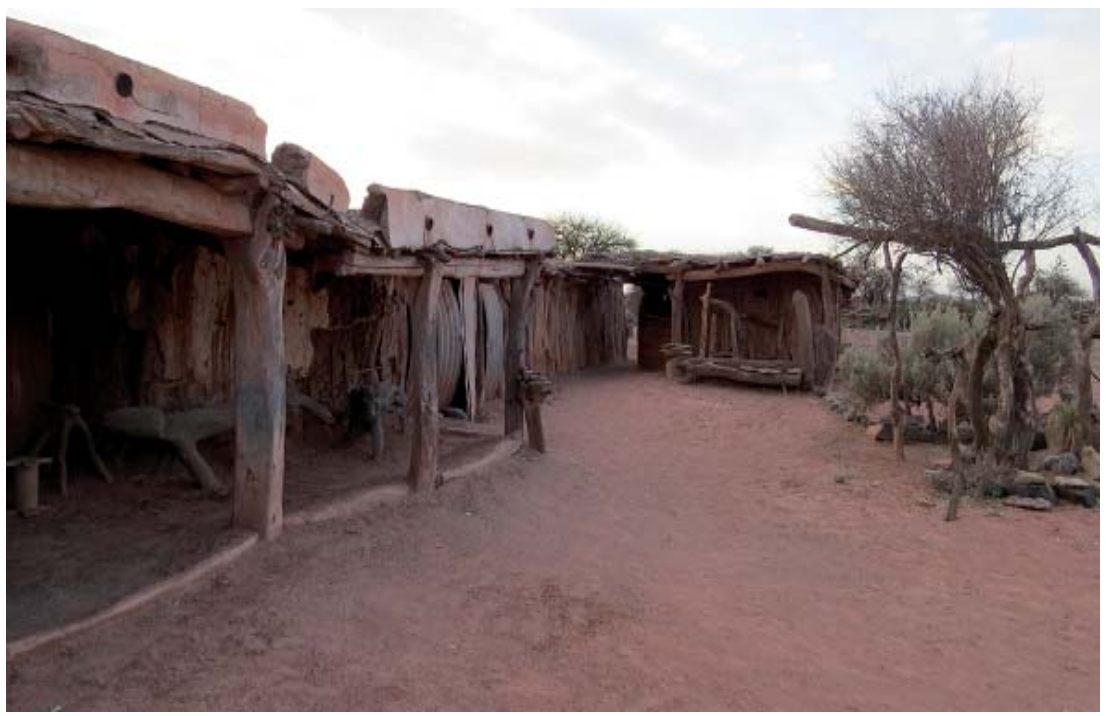

Nota. Archivo fotográfico personal.

\section{Figura 3}

Casa de don Benedicto de los Ángeles Herrera

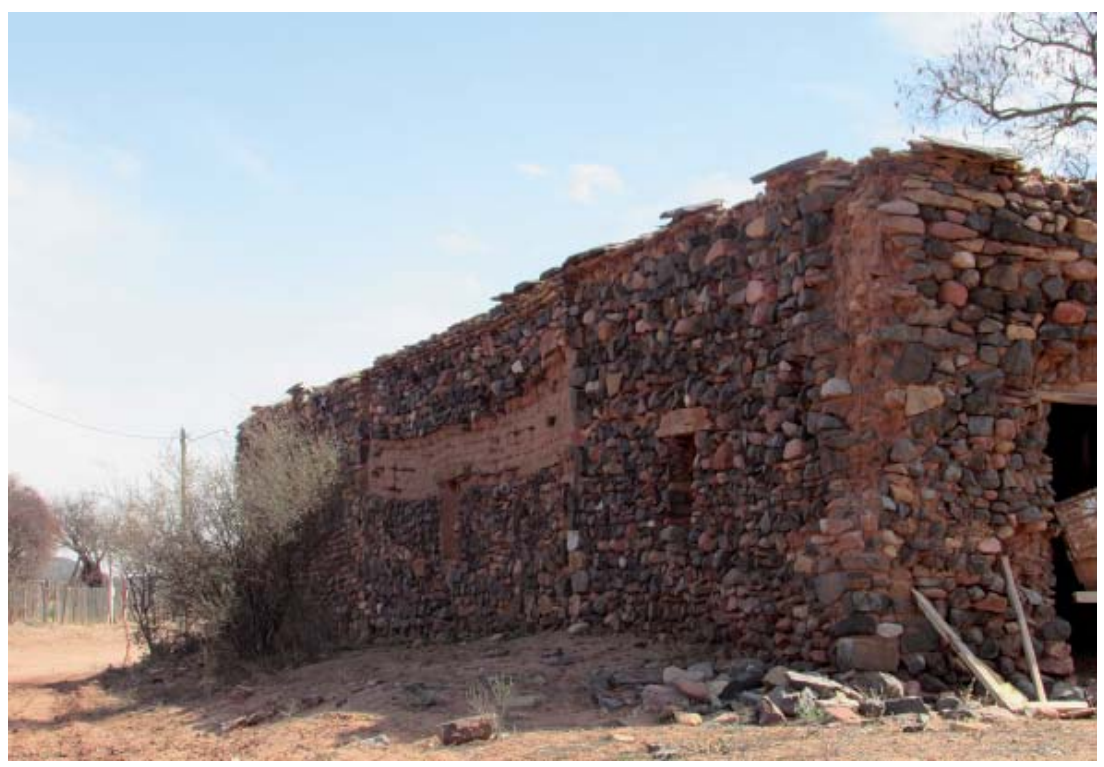

Nota. Archivo fotográfico personal. 
4. Antiguo pozo balde (Fig. 5). Una las construcciones típicas de la zona es el aparejo que se utiliza para subir agua de los pozos. Formado por una doble viga de algarrobo, sostenida y apoyada en horcones, con una roldana de madera al medio que engancha la soga y permite subir el balde lleno. La abertura del pozo se cubre con maderas o se protege con una pared baja de piedra o adobes. Antiguamente, para saber dónde cavar para conseguir agua, se buscaba un lugar donde creciera el atamisque o matagusanos (Atamisquea emarginata), un arbusto frecuentemente ubicado en el bajo o en zonas de cauces temporarios (Rotondaro, 2007). Los pobladores contaron que también usaban como planta indicadora al jume (Suaeda divaricata).

5. Iglesia San José (Fig. 6). Fue construida por los pobladores de la zona hace unos cien años. Presenta una nave central y una sacristía en uno de los lados largos. Al frente posee un atrio amplio y un campanario sencillo con dos revoques con pintura blanca a la cal por fuera y por dentro. Los techos son de cumbreros y vigas de rollizos de algarrobo, caña tejida con alambre y barnizadas y una cubierta de torta de barro con una capa de material más duro (mezcla de tierra, cemento, cal y arena). En el año 1922, desde Chile trajeron a lomo de mula las imágenes de cuatro santos: San Ramón, San Agustín, San Juan Bautista y San José; este último es el santo de la capilla. Antes de su inauguración (1925), la iglesia de San José funcionaba en la casa de Benedicto Herrera.

6. Represa de Los Baldecitos (Fig. 7). Fue construida con máquina en el año 1990. Los animales domésticos (vacas, caballos, burros, cabras) y silvestres de la zona hacen uso del agua de la represa para consumo. Suelen avistarse aves como el tero real (Himantopus mexicanus) y el macá plateado (Podiceps occipitalis).

Figura 4

Casa de la infancia de doña Alba

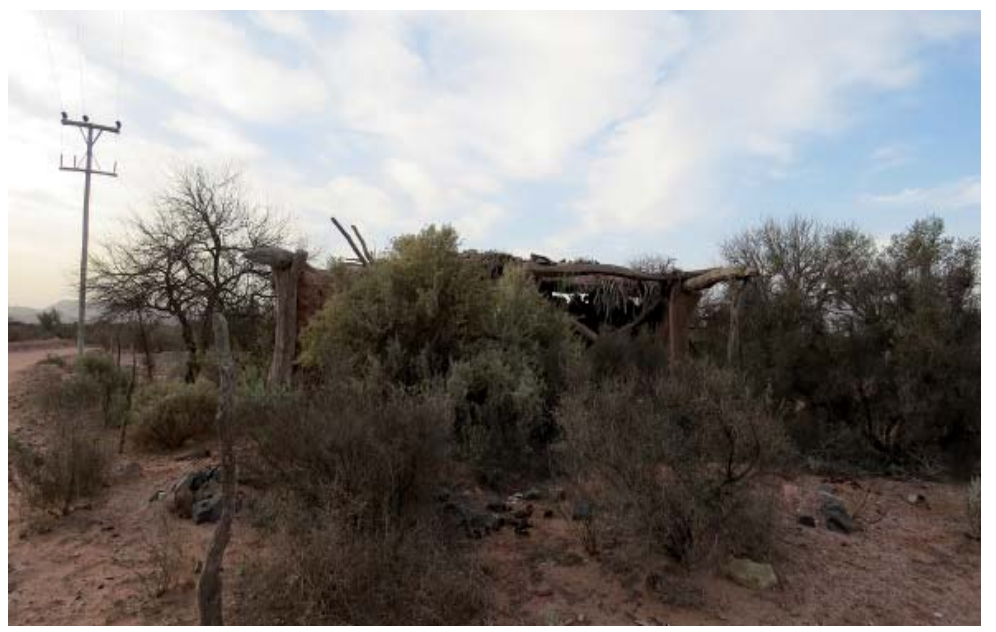

Nota. Archivo fotográfico personal. 


\section{Figura 5}

Antiguo pozo balde

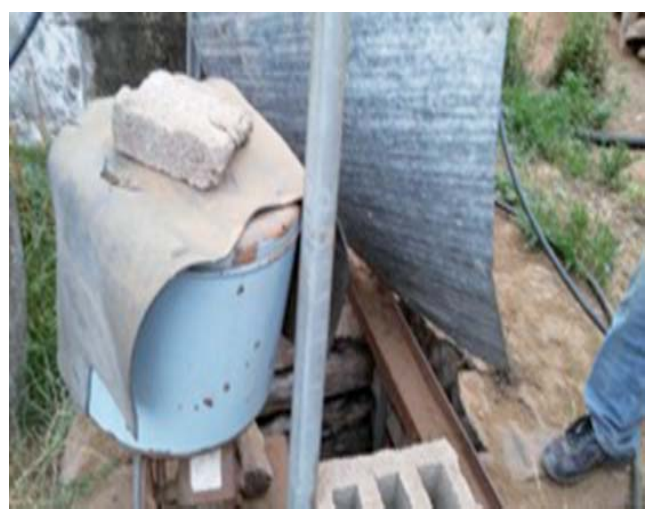

Nota. Archivo fotográfico personal.

\section{Figura 6}

Iglesia San José

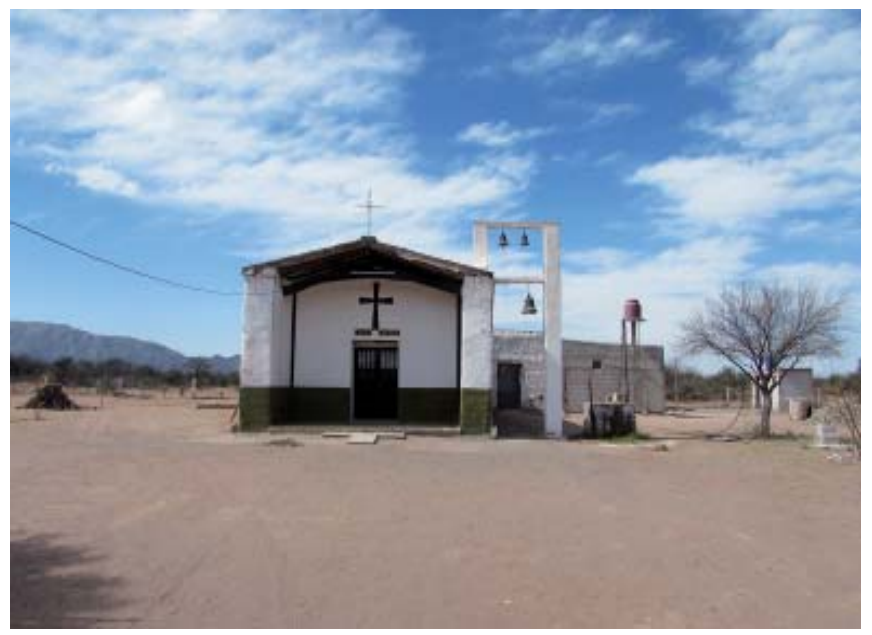

Nota. Archivo fotográfico personal.

7. Represa de los Soria (Fig. 8). Se construyó en el año 1910, por Benedicto Herrera con ayuda de los vecinos. Fue la segunda represa del pueblo y aún se puede acceder a ella entrando por un costado de la ruta. Actualmente la vegetación, particularmente algarrobos (Prosopis flexuosa), la han cubierto.

8. Primera represa de Los Baldecitos (Fig. 9). Conocida en el pueblo como la represa de los Herrera. Fue construida por Saúl Herrera con la ayuda de los vecinos en 1905. Se dejó de usar hace pocos años debido a problemas de tenencia de la tierra. Esta represa fue un punto en el que se cruzaban los caminos de los arrieros que se dirigían a Jáchal y a San Agustín. 


\section{Figura 7}

\section{Represa Los Baldecitos}

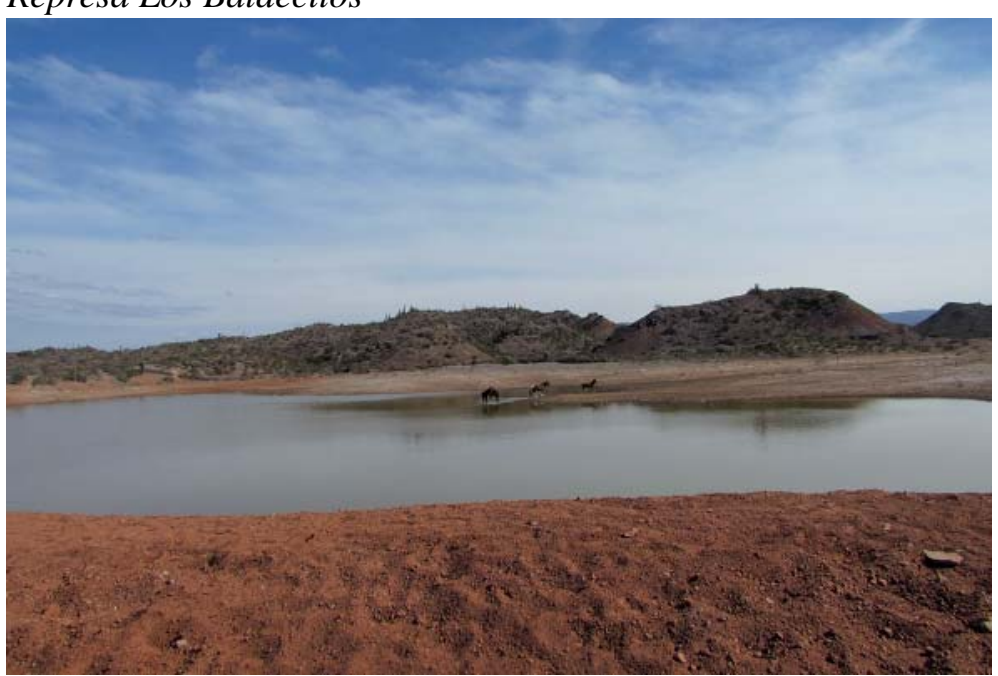

Nota. Archivo fotográfico personal.

\section{Figura 8}

Represa los Sorias

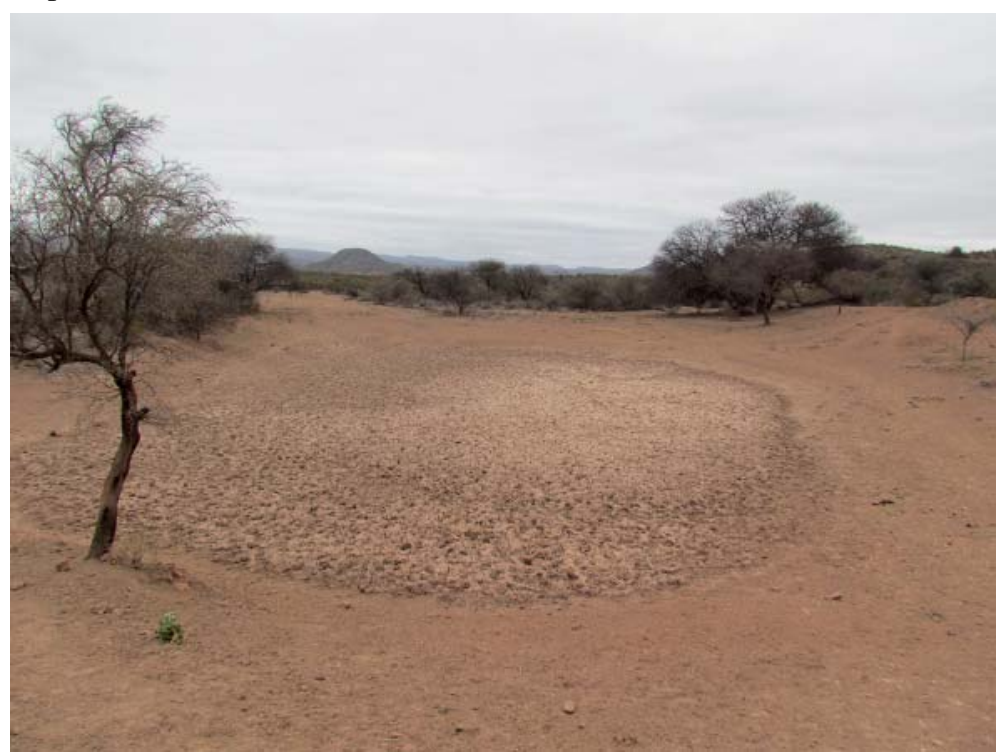

Nota. Archivo fotográfico personal. 
9. Casa de Rosiel Soria (Fig. 10). Tiene paredes donde se colocaba piedra con piedra. Se ubica camino al PPI y cerca de la represa de los Soria. Esta construcción data de antes del año 1915.

10. Cementerio (Fig. 11). Es el más antiguo de la zona y allí se enterraban también a pobladores vecinos y personas de paso, como los arrieros. Las tumbas más antiguas datan del año 1910 y 1915 . El cementerio se sigue utilizando en la actualidad.

11. Escuela Armada Argentina (Fig. 12). Desde el año 1906 la escuela funcionaba en las casas de los vecinos. El almirante Pedrozo tuvo la iniciativa de construirla en un terreno donado por Saúl Herrera. Los obreros y los materiales provenían de las zonas cercanas. Fue inaugurada el 17 de agosto de 1960.

12. Los bañados (Fig. 13). Estos sitios se utilizaron hasta hace pocos años para cultivar maíz y zapallo. Están ubicados en una zona de bajos, donde se acumula el agua, y la tierra es muy fértil. Los pobladores tienen distintas parcelas, separadas por cercos de ramas para demarcarlas y para evitar la entrada del ganado. Como no se usa desde hace unos años, las parcelas están cubiertas por chamico (Datura ferox), una maleza tóxica que crece en suelos removidos.

\section{Figura 9}

Represa Los Baldecitos

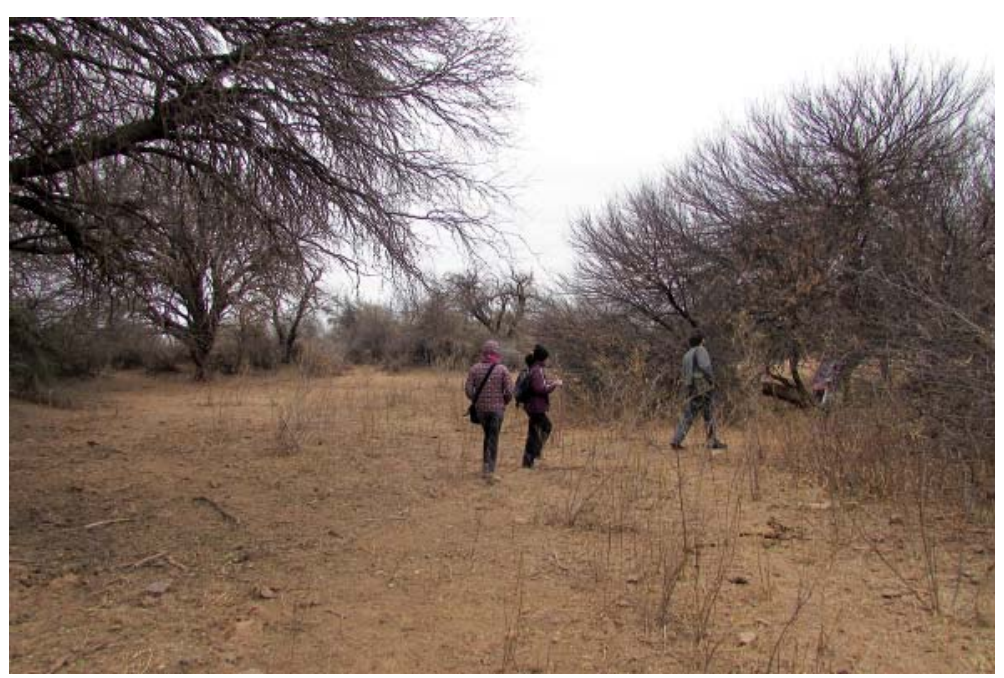

Nota. Archivo fotográfico personal. 
Figura 10

Casa de Rosiel Soria

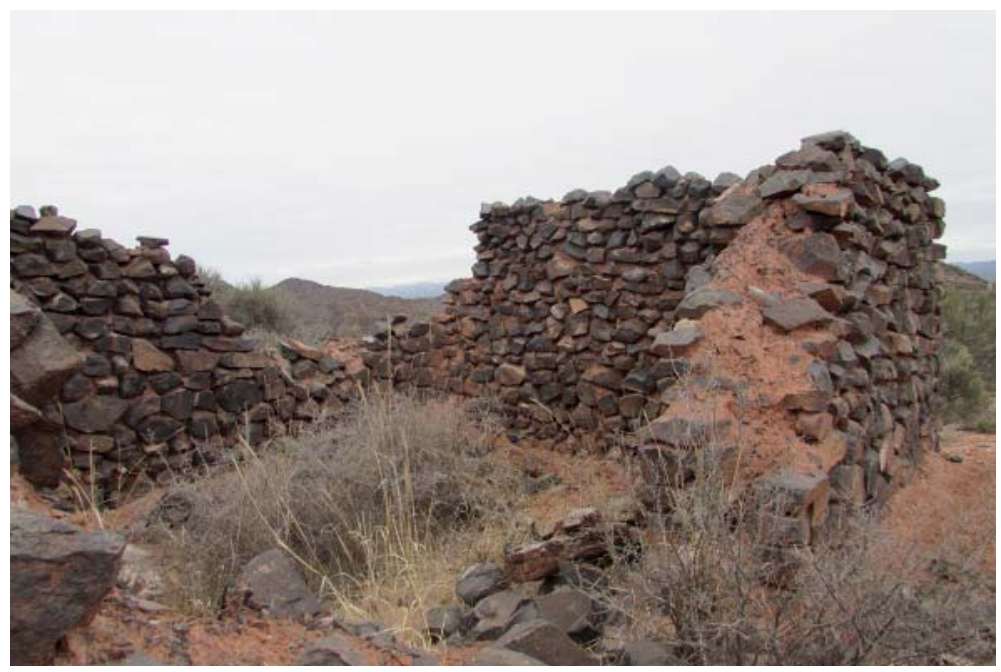

Nota. Archivo fotográfico personal.

Figura 11

\section{Cementerio}

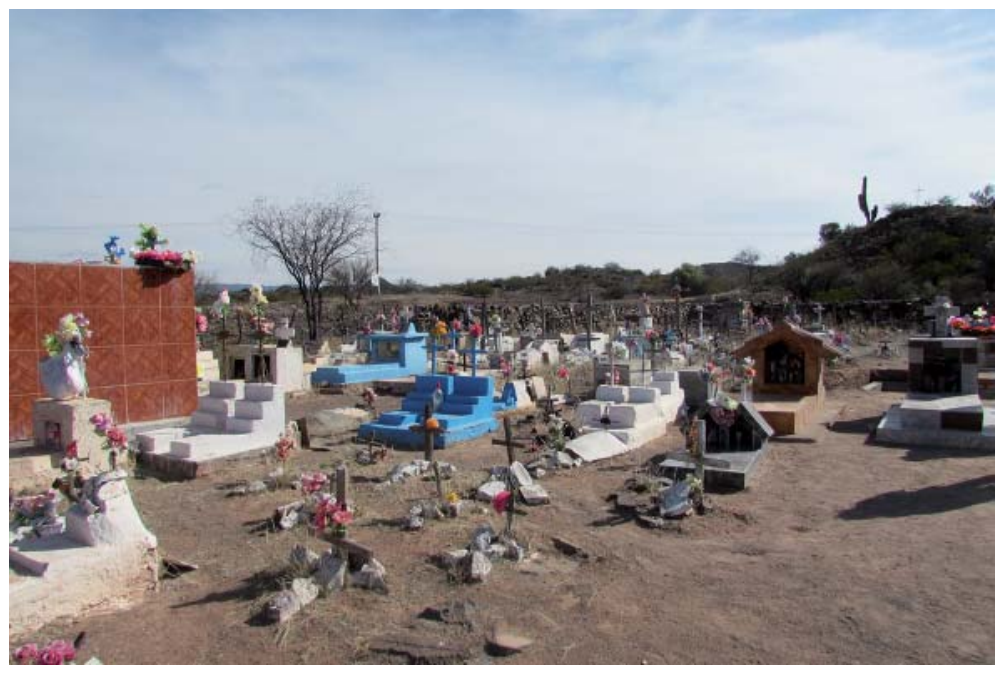

Nota. Archivo fotográfico personal. 
LOS BALDECITOS (SAN JUAN, ARGENTINA) COMO PORTAL DEL PARQUE PROVINCIAL ISCHIGUALASTO (PATRIMONIO DE LA HUMANIDAD): PUESTA EN VALOR DEL PATRIMONIO CULTURAL TANGIBLE E INTANGIBLE

Figura 12

Escuela Armada Argentina

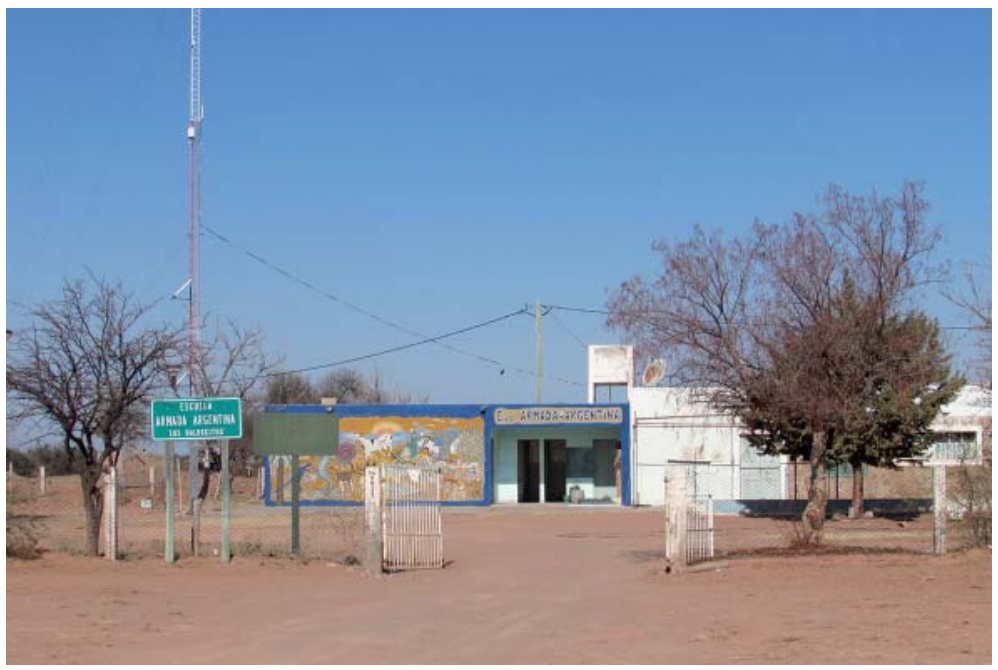

Nota. Archivo fotográfico personal.

Figura 13

Los bañados

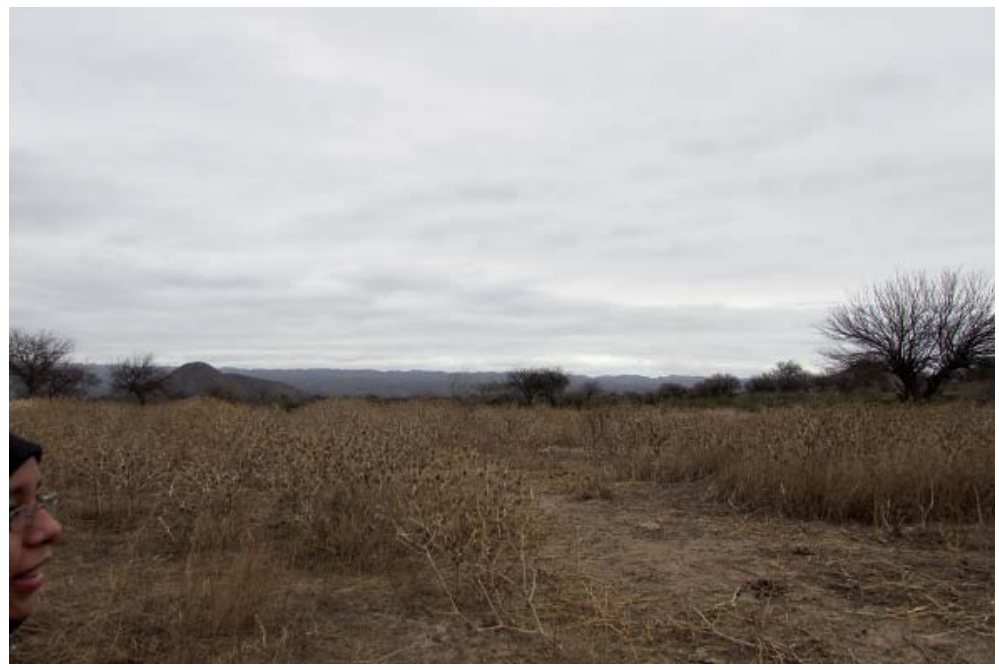

Nota. Archivo fotográfico personal. 


\section{El patrimonio cultural intangible}

Las entrevistas en profundidad brindaron información acerca de la historia de la localidad y sus habitantes. Una de las entrevistadas (María) cuenta lo siguiente:

La gente de antes trabajaba de la crianza de animales, de los pocos que tenían, porque no tenían muchos. Y la comida era la que sembraban, como el zapallo, el maíz. Las mujeres trabajaban en telares y en bordado. Las cosas que hacían tejiendo y bordando, seguramente las vendían y con eso subsistían. Porque en esos años pasaba gente por el pueblo que traían negocios de otro lado y ellas hacían esas cosas y vendían y cambiaban, más por ropa. Porque ellos tenían sus animales y se mantenían de la carne, de la leche. Cuando era joven iba a comprar al Valle. Mi abuela tejía muchas frazadas, jergones que ellos decían, y los cambiaba en el primer negocio que hubo en el Valle. Entonces nosotros llevábamos telas, alforjas y cambiábamos por harina, fideos, azúcar, la atábamos bien y la cargábamos en el burro.

Uno de los pobladores, de nombre José, cuenta:

Trabajé muchos años en la mina de mica, que se empezaron a explotar en el año 1950. La usaban para la resistencia de la plancha, para los vidrios. De acuerdo al tamaño era lo que valía. También se sacaba el cuarzo y había que trabajarlo con explosivos. Los explosivos tenían un fulminante que mordíamos con los dientes y lo apretábamos para que quede y que no se salga la mecha. No teníamos pinzas. Si había buena producción se ganaba buena plata. Era muy sacrificado, pero era el único trabajo, aparte de los animales, pero eso era para supervivencia. A veces se iba a la mica y volvíamos sin nada porque no sacábamos nada.

La estrecha vinculación con el PPI se establece aún antes de la creación del parque, cuando los pobladores actuaban como guías de los paleontólogos. Es más, según el relato de los pobladores, el interés por la riqueza paleontológica del parque comienza cuando un conocido habitante de Los Baldecitos, don Victorino Herrera, encuentra un resto fósil y lo entrega a un investigador del Museo de La Plata. Años después, comenzaron las exploraciones y excavaciones; se contó con la ayuda de guías y trabajadores locales.

Algunas leyendas del lugar todavía se reproducen oralmente entre los pobladores. Relatan historias relacionadas con riquezas o tesoros escondidos que aún no han aparecido. Una de ellas es la leyenda del gaucho Navarro, relatada por uno de los informantes:

Por el pueblo Los Baldecitos pasaba el camino de los arrieros y el gaucho Navarro se ponía en el portezuelo. Él esperaba a los arrieros que pasaban por ahí, los mataba y les quitaba la plata y los enterraba. Se han encontrado muchísimos difuntos y cosas enterradas en el portezuelo. El gaucho Navarro se había criado en un pueblo cercano. La madre se casó con otro señor que no era el padre del gaucho. Ellos ocupan una empleada para lechadora, para que saque la leche, pero ambos, hijastro y padrastro se enamoran de la empleada, entonces empieza una discusión, hasta que un día se pusieron a pelear y en esos años cada uno tenía su cuchillo atravesado en la cintura, entonces 
el viejo le saca ventaja y le da la orden a la madre que no le diera de comer y que no lo dejara entrar más a la casa. Entonces la madre, a escondidas, lo alimentaba. Y él venía, comía y se iba porque el padrastro lo iba a matar. Es por eso que se empezó a ir y empezó a matar. Dicen que de la zona del portezuelo hay muchísimas cruces, todos esos muertos los mataba él, mataba mucha gente. Hasta que lo atraparon. Se dice que el gaucho Navarro siempre andaba donde se hacía cambalache (intercambio de mercadería), él se arrimaba, la gente no le decía nada porque le tenía miedo y quizá también un poco de lástima. El gaucho Navarro parecía que tenía una noviecita y ella lo invitó para su casa y llamó a la policía y lo arrestaron. Se lo llevaron a Córdoba y allí lo fusilaron.

El gaucho Navarro, así como Doña Martina Chapanay, Santos Guayama y el gaucho Donoso, fueron auténticos bandidos cordilleranos, protagonistas de numerosas fechorías (Rolandi et al., 2008).

Otra leyenda es la de los tres cuellos de guanacos, que cuenta:

Como la zona de los Baldecitos ha sido una zona de paso, había tres curas que iban escapando y llevaban oro dentro de bolsas hechas con cuero de cuello de guanaco. Estos curitas enterraron el oro enfrente del Cerro Morado. Mucha gente ha buscado ese tesoro cavando, pero nunca lo pudieron encontrar. Se dice que había un cardón y se cree que ese cardón tenía un hueco, mirando por ese hueco, no se sabe a cuantos metros, estaba el lugar donde los curitas que dejaron el oro. Los curitas habían pasado para el lado de Chile y los llevaron presos. Muchos han buscado ese oro, pero se dice que quien esté destinado a encontrarlos no tiene que tener interés.

El Cerro Morado, donde se dice está enterrado el oro, se ubica dentro del parque. Aún pueden verse en la cima del cerro restos de un pozo que se excavó a mediados del siglo XX para buscar las bolsas de oro. Las bolsas eran de cuero de cuello de guanaco, un camélido nativo que habita la región (Lama guanicoe).

La leyenda del arriero es otro relato propio de Los Baldecitos. Cuentan:

[que] En los años en que los arrieros pasaban por el Parque Provincial Ischigualasto, uno de ellos venía de Jáchal e hizo noche en la Quebrada de La Chilca. Ató su mula y se propuso pasar la noche. La mula estaba muy inquieta, se movía de un lado para el otro y llegó un momento en que rompió el lazo y se fue. Y el arriero sentía pasos, pensó que era un puma al principio. Tendió la cama, puso el apero en el piso y se acostó boca abajo con un cuchillo bajo su pecho; al fuego le echó bastante leña. Sintió que se acercaban pasos de persona y el arriero le preguntó: «¿Sos de esta vida o de la otra?» A lo que le responden: «De la otra». El arriero podía ver a su costado las piernas de esa persona. Entonces le preguntó que quería. Y le respondió que andaba penando porque le debía una promesa a una virgen y quería que él se la cumpliera, así él podía descansar en paz. En tal lado le dijo que había un cántaro que tenía oro y que tenía que sacarlo para que le cumpliera la promesa. El arriero pensó como iba a llegar a su casa porque había una sequía muy grande, el alma en pena le dijo que no se hiciera problema que él lo iba a ayudar. Y se fue. Al otro día temprano, el arriero se cargó todo al hombro y caminó como pudo. Al mediodía hubo una 
tormenta tremenda y él se había quedado sin agua así que la lluvia lo ayudó. El arriero pudo cumplir la promesa. Al poco tiempo murió.

\section{Relevamiento de la planta turística}

Se consideran los servicios que ofrece la localidad Los Baldecitos de alojamiento, comida, información turística y transporte público.

\section{Categoría hospedaje}

Tipo: extrahotelero

Medio de acceso: vehículo particular.

Establecimiento:

- Hospedaje Leandra, $n .^{\circ}$ de habitaciones: 6 , n. ${ }^{\circ}$ de plazas: 20, desayuno para 32 personas.

- Hospedaje El Padrino, n. ${ }^{\circ}$ de habitaciones: 1, n. ${ }^{\circ}$ de plazas: 4 , ofrece comidas.

- Hospedaje Benjamín, n. ${ }^{\circ}$ de habitaciones: 2, n. ${ }^{\circ}$ de plazas: 10.

\section{Categoría alimentación}

Tipo: restaurante

Medio de acceso: vehículo particular.

- Comedor Alba, comida tradicional rural (p. ej., pastel de papa, chivito al vino, empanadas).

- Comedor Jacinta, capacidad: 36 personas.

\section{Categoría otros servicios}

Tipo: información

Medio de acceso: vehículo particular.

- Oficina de informe. Brinda indicaciones sobre cómo llegar al Parque Provincial Ischigualasto y los horarios de visita. Algunas veces los turistas preguntan qué actividades se pueden realizar en el pueblo.

\section{Categoría transporte}

Tipo: terrestre

Subtipo: empresa de transporte público.

- Empresa Vallecito. Existe un servicio que, saliendo de San Agustín de Valle Fértil, pasa por los pueblos de Balde del Rosario y Los Baldecitos, y luego se dirige a La Rioja.

- Subtipo: red de carreteras, Ruta Nacional n. ${ }^{\circ}$ 150, tipo de calzada: asfalto; estado de la ruta: en condiciones. En su recorrido de 389 kilómetros, conecta el km 356 de la Ruta Nacional n. ${ }^{\circ}$ 38, a las 
afueras de la localidad riojana de Patquía, con el paso montañoso internacional Agua Negra, a 4779 m s. n. m., en la frontera chilena. La calzada continúa en la vecina nación como ruta 41-CH, que conduce a la ciudad chilena de La Serena.

\section{Categoría acontecimientos programados}

- $\quad$ Fiesta de San José. Se realiza todos los años, el 19 de marzo.

\section{Categoría infraestructura}

Tipo: red de seguridad

- Puesto policial, funciona desde el año 1950.

\section{Relevamiento del interés de turistas y pobladores por el desarrollo del turismo en la localidad}

Según resultados de las encuestas: 70\% de las personas remarcó los beneficios económicos que la actividad turística otorga a la localidad, y 50\% considera que el turismo significa crecimiento a nivel local; menos del $10 \%$ de los encuestados manifestaron efectos negativos del turismo, como impactos ambientales o amenaza a las tradiciones locales. El 90\% de los turistas del PPI encuestados respondió que participaría de un circuito turístico en Los Baldecitos. Sin embargo, tanto pobladores como turistas (70\% de los encuestados) opinan que la localidad no se encuentra actualmente preparada para recibir gran número de turistas.

\section{Análisis FODA}

La matriz FODA es una herramienta que se utiliza para conocer la situación real en que se encuentra una organización, empresa, o proyecto, y planear una estrategia de futuro. Este análisis surge del campo empresarial. Los elementos internos que se deben analizar corresponden a las fortalezas y debilidades que se tienen respecto a la disponibilidad de recursos de capital, personal, activos, calidad de producto, estructura interna y de mercado, percepción de los consumidores, entre otros. El análisis externo permite fijar las oportunidades y amenazas que el contexto puede presentarle a una organización.

De la combinación de estas variables internas y externas se obtiene que las oportunidades más las fortalezas representan las potencialidades; las amenazas más las debilidades representan las limitaciones; las fortalezas más las amenazas manifiestan los riesgos; y las debilidades más las oportunidades representan los desafíos. Aplicando el análisis FODA, al caso de estudio presentado en este trabajo, se elaboró la matriz que se presenta en la Tabla 1.

De acuerdo a las variables FODA, se observa una mayor incidencia de los aspectos internos al sitio en sus variables positivas (fortalezas $=4.42$ por sobre las oportunidades $=4.28$ ), pero una mayor incidencia de los aspectos externos en sus variables negativas (amenazas $=4.00$ por sobre las debilidades $=3.83$ ). Por otro lado, se observa que los aspectos positivos (oportunidades + fortalezas $=4.35$ ) poseen un grado de incidencia mayor que los aspectos negativos (amenazas + debilidades $=3.91$ ). 
Tabla 1

Matriz de fortalezas, debilidades, oportunidades y amenazas para el desarrollo de propuestas de turismo sustentable relacionadas con el patrimonio cultural de Los Baldecitos (San Juan, Argentina)

\begin{tabular}{|c|c|c|c|}
\hline Fortalezas & Debilidades & Oportunidades & Amenazas \\
\hline $\begin{array}{l}\text { La localidad de Los } \\
\text { Baldecitos posee una gran } \\
\text { riqueza de atractivos a nivel } \\
\text { cultural e histórico. (5) }\end{array}$ & $\begin{array}{l}\text { Algunos de los atractivos de } \\
\text { la localidad no se encuentran } \\
\text { en condiciones de seguridad, } \\
\text { mantenimiento y limpieza. (3) }\end{array}$ & $\begin{array}{l}\text { Buena disposición de los } \\
\text { pobladores hacia el } \\
\text { desarrollo de propuestas } \\
\text { turísticas a nivel provincial } \\
\text { y local. (5) }\end{array}$ & $\begin{array}{l}\text { Falta de promoción de la } \\
\text { localidad Los Baldecitos a } \\
\text { nivel nacional y regional. (4) }\end{array}$ \\
\hline $\begin{array}{l}\text { Proximidad a la villa } \\
\text { cabecera departamental } \\
\text { (Villa San Agustín), donde } \\
\text { se concentra la mayor } \\
\text { planta turística; también } \\
\text { está próximo a la } \\
\text { provincia de La Rioja. (4) }\end{array}$ & $\begin{array}{l}\text { Carencia de información } \\
\text { histórica sistematizada de } \\
\text { la localidad para ofrecer a } \\
\text { los turistas. (4) }\end{array}$ & $\begin{array}{l}\text { Turistas que visitan el PPI } \\
\text { desean poder realizar un } \\
\text { circuito cultural en la } \\
\text { localidad Los Baldecitos. } \\
\text { (5) }\end{array}$ & $\begin{array}{l}\text { Existen mejores facilidades } \\
\text { para el turismo } \\
\text { (alojamiento, comida, etc.) } \\
\text { en la localidad vecina } \\
\text { Baldes del Rosario. (4) }\end{array}$ \\
\hline $\begin{array}{l}\text { Existencia de otros } \\
\text { atractivos reales y } \\
\text { potenciales cercanos. (3) }\end{array}$ & $\begin{array}{l}\text { Acción erosiva natural de } \\
\text { los atractivos culturales por } \\
\text { acción del viento, lluvia, } \\
\text { sismos, aluviones y } \\
\text { amplitud térmica. (3) }\end{array}$ & $\begin{array}{l}\text { Creciente demanda } \\
\text { turística por nuevos } \\
\text { productos, entre ellos, los } \\
\text { de índole cultural y } \\
\text { temático. (4) }\end{array}$ & $\begin{array}{l}\text { No se considera a Los } \\
\text { Baldecitos cuando se } \\
\text { promociona turísticamente } \\
\text { al departamento Valle Fértil. } \\
\text { (4) }\end{array}$ \\
\hline $\begin{array}{l}\text { Sitio con gran cantidad de } \\
\text { casas antiguas } \\
\text { construidas a mano por } \\
\text { antiguos pobladores. (4) }\end{array}$ & $\begin{array}{l}\text { Algunas vías de acceso se } \\
\text { encuentran en malas } \\
\text { condiciones cuando hay } \\
\text { lluvias. (4) }\end{array}$ & $\begin{array}{l}\text { Puesta en valor de los } \\
\text { productos autóctonos. (4) }\end{array}$ & $\begin{array}{l}\text { Pandemia por la COVID-19 } \\
\text { exigirá diseñar y cumplir } \\
\text { protocolos sanitarios que } \\
\text { generarán limitaciones } \\
\text { operativas y aumento de } \\
\text { costos directos e } \\
\text { indirectos. (4) }\end{array}$ \\
\hline $\begin{array}{l}\text { Actitud favorable de los } \\
\text { pobladores locales y los } \\
\text { turistas que visitan el PPI }\end{array}$ & $\begin{array}{l}\text { Falta de hospedajes y } \\
\text { restauración categorizados } \\
\text { en la localidad. (5) }\end{array}$ & $\begin{array}{l}\text { Existencia de líneas de } \\
\text { créditos nacionales y } \\
\text { provinciales. (5) }\end{array}$ & $\begin{array}{l}\text { La crisis de la COVID-19 } \\
\text { despertará la desconfianza } \\
\text { de visitar lugares turísticos. }\end{array}$ \\
\hline
\end{tabular}

hacia el desarrollo del

turismo en Los Baldecitos.

(5)

Pobladores con mucha información histórica de la localidad y conocimientos sobre flora y fauna autóctona. (5)

Los pobladores tienen en mente dar un giro a la imagen de la localidad mediante la puesta en valor de la misma. (5)
La localidad vecina, Baldes del Rosario, está mejor posicionada en la mente del consumidor. (4)
Situación macroeconómica nacional que torna a nuestro país en un destino barato para el turismo extranjero. (3)

La inexistencia de casos positivos de la COVID-19 en el área y su cualidad de espacio rural, sin aglomeraciones urbanas, beneficiará su posicionamiento como destino saludable libre de la COVID-19. (4)

Total: 31 (promedio $=4.42) \quad$ Total: $23($ promedio $=3.83) \quad$ Total: $30($ promedio $=4.28) \quad$ Total: $20($ promedio $=4.00)$ 


\section{Discusión}

La localidad de Los Baldecitos tiene una rica historia como testigo del paso de los arrieros que circulaban entre Chile y Argentina cruzando la cordillera. Desde sus primeros asentamientos, los pobladores utilizaron para su sustento los bienes naturales que ofrece el ecosistema árido: animales y plantas silvestres, agua subterránea. Ellos participaron del desarrollo de las actividades mineras de mica y cuarzo. Pero sobre todo, la historia de esta localidad se vincula fuertemente al PPI. Algunos pobladores de Los Baldecitos fueron guías de los primeros paleontólogos (como don Victorino Herrera), y muchos de ellos trabajaron, y aún trabajan, como guías de turistas, guardaparques y prestadores de servicios turísticos.

Las entrevistas a informantes claves permitieron relevar los potenciales puntos de interés del patrimonio cultural, que se relacionan principalmente con las primeras construcciones de casas familiares, represas de agua, pozos balde, sitios de cultivo, iglesia y escuela. Esos atractivos se encuentran ubicados en esta localidad o muy cerca de ella, con acceso a pie, permitiendo ser visitados por los turistas que pernoctan en la localidad antes o después de estar en el PPI. Las entrevistas también pusieron en evidencia que, más allá del patrimonio cultural tangible, subyace un importante patrimonio cultural intangible, que se refleja en costumbres y leyendas.

También se analizó la planta turística, infraestructura y superestructura en la zona, lo que permitió determinar que la localidad no está preparada para la llegada masiva de turistas, pero sí para el alojamiento de pocos turistas de paso que visitan el PPI. Las encuestas evidenciaron que tanto turistas como pobladores están interesados en la puesta en marcha de iniciativas turísticas.

Luego de identificar los atractivos de la localidad, la oferta de planta turística y el escenario actual de pandemia, se realizó una ponderación de los distintos ítems y un análisis FODA para detectar fortalezas, oportunidades, debilidades y amenazas de la localidad de Los Baldecitos desde el punto de vista turístico. Del análisis se desprende una mayor incidencia de los aspectos internos del sitio en sus variables positivas (fortalezas por sobre oportunidades) pero una mayor incidencia de los aspectos externos en sus variables negativas (amenazas por sobre debilidades). Esto revela, por un lado, el impacto que ha tenido la pandemia en la realidad de destinos emergentes del país, aún cuando estuvieran alejados de los grandes centros urbanos donde la pandemia ha generado mayores consecuencias. Por otro lado, este resultado también muestra la falta de participación y soporte por los particulares y organismos del Estado, tanto a nivel provincial como nacional, para la conservación, desarrollo y promoción de localidades adyacentes a espacios conservados como el PPI.

Los aspectos positivos que representan potencialidades (oportunidades y fortalezas), poseen un grado de incidencia mayor que los aspectos negativos que representan limitaciones (amenazas y debilidades), lo cual muestra que la localidad de Los Baldecitos cuenta con recursos para realizar una oferta interesante, por ejemplo: ubicación geográfica privilegiada (sobre el corredor bioceánico, localidad más cercana al PPI y cercana a la villa cabecera del departamento), represa con uso actual, casas antiguas, pozos baldes y leyendas, además de su cualidad de área libre de COVID-19, parámetro muy importante para el futuro proceso de reactivación del turismo sobre nuevos paradigmas vinculados a lo sanitario y volcados al desarrollo de actividades en entornos naturales. 
Así mismo, considerando las debilidades y las oportunidades, se puede pensar en los desafíos para el desarrollo de propuestas turísticas relacionadas con el patrimonio cultural. Estos desafíos se relacionan con la falta de mantenimiento de los puntos de interés, especialmente las casas y pozos baldes antiguos, y la falta de promoción y soporte desde el departamento, la provincia y la nación. Esto queda en evidencia cuando se observa que, a pesar que el PPI es el área protegida más visitada de la provincia y con mucha promoción a nivel provincial y nacional, el efecto derrame de los beneficios del parque no se manifiestan en la localidad más cercana, Los Baldecitos.

Es importante remarcar que, a nivel mundial y en un escenario pospandemia, la visión de la OMT (World Tourism Organization [UNWTO], 2020) se enfoca fuertemente en la recuperación de un turismo responsable para las personas, el planeta y la prosperidad, en relación con la salud pública, la inclusión social, la conservación de la biodiversidad, la atención hacia el cambio climático, la economía y la gobernanza. En este marco, se reconoce que el turismo genera puestos de trabajo en las comunidades locales, incluso por medio de economías informales y, por lo tanto, la recuperación responsable del turismo debe incluir ayudas especiales para los grupos más vulnerables. Entonces, se puede esperar que mediante la generación de nuevos servicios e iniciativas creativas, algunos destinos como Los Baldecitos, puedan tener la oportunidad de recibir beneficios del turismo sustentable que integre el patrimonio biocultural local.

Si ocurre una reactivación del turismo interno, dirigido a sitios ubicados en entornos naturales, con atractivos dispersos en el espacio y al aire libre, Los Baldecitos podría constituirse en un destino elegido por el turismo. De acuerdo a los resultados del presente estudio, se considera que es posible el desarrollo de proyectos de turismo sustentable enfocados en el patrimonio cultural de la localidad. Para ello, es necesario que los pobladores tomen la decisión de poner en movimiento proyectos y que los beneficios que emanan de la estrecha relación con el parque y de la nueva tendencia mundial hacia la recuperación del turismo por intermedio de la sustentabilidad, se concreten con ayuda económica y soporte técnico para las iniciativas de los pobladores. Estas iniciativas deberán contemplar mejoras en los servicios, ajustadas a las nuevas formas de cuidado de la salud.

\section{Conclusiones}

Bajo los nuevos paradigmas de conservación de la naturaleza y de prácticas sustentables desde lo ambiental, sanitario, cultural y económico, las áreas protegidas deben conservar tanto la diversidad biológica como la diversidad cultural. Esta diversidad cultural se manifiesta por medio del patrimonio cultural de las localidades que están dentro o en la zona de influencia de las reservas. Una atención especial deben recibir estas poblaciones, para que el efecto derrame de los beneficios del turismo en áreas protegidas también las beneficie mediante iniciativas de turismo sustentable. Las prácticas turísticas pospandemia deberán considerar, no solo los protocolos de salubridad para el turista, sino también a la comunidad local y prestadores; así como a los actores designados para el control y protección de los bienes que se quieren preservar. De esta manera, la naturaleza y la salud estarán integrados en los destinos exitosos. 


\section{Agradecimientos}

Agradecemos la colaboración y amabilidad de los pobladores de Los Baldecitos. También nuestra gratitud para la ingeniera Carolina Moreno, por su colaboración al brindarnos información sobre las especies de flora y fauna y cómo son usadas por los pobladores. Asimismo, agradecemos los constructivos comentarios del Comité Editorial. El estudio fue parte de la tesis de grado de Yamila Andrada para la Licenciatura en Turismo de la Universidad Nacional de San Juan, Argentina.

El trabajo se realizó en el marco del Proyecto La chica, el retamo y el algarrobo: especies paraguas para la conservación del Bosque Nativo del Parque Provincial Ischigualasto. Interacciones biológicas, efectos de actividades humanas y su mitigación (Directora técnica: Stella Giannoni), con financiamiento del Fondo para el Enriquecimiento y la Conservación de los Bosques Nativos (Programa de Conservación de Bosques NativosLey . $\left.^{\circ} 26331\right)$.

\section{Referencias}

Acevedo, M. (2006). Ecoturismo comunitario en la Ecoregión Valdiviana. En R. P. Catalán, A. Wilken, D. Kandzior, D. Tecklin y H. Burschel (Eds.), Bosque Nativo y Comunidades Locales del Sur de Chile (pp. 291-299). Editorial Universitaria.

Ament, J. M. y Cumming, G. S. (2016). Scale dependency in effectiveness, isolation, and social-ecological spillover of protected areas. Conservation Biology, 30(4), 846-855.

Blitzer, E. J., Dormann, C. F., Holzschuh, A., Klein, A., Rand, T. A. y Tscharntke, T. (2012). Spillover of functionally important organisms between managed and natural habitats. Agriculture, Ecosystems and Environment, 146, 34-43.

Código de Ética de la Sociedad Latinoamericana de Etnobiología (SOLAE). (2016). Código de ética para la investigación, la investigaciónacción y la colaboración etnocientífica en América Latina. Etnobiología, 14. https://revistaetnobiologia.mx/index.php/etno/article/view/ 338

Diekmann, D. A. y Smith, M. K. (Eds.) (2003). Ethnic and minority cultures as tourist attractions. Channel View Publications.

Fennell, D. A. y Ebert, K. (2004). Tourism and the precautionary principle. Journal of Sustainable Tourism, 12, 461-479.

Fuentes, R. (Ed.) (1995). El turismo rural en España. Especial referencia al análisis de la demanda. Instituto de Estudios Turísticos.

Michieli, C. T. (Ed.) (1994). Antigua historia de Cuyo. Ansilta Editora.

Morillo, M. C. (2011). Turismo y producto turístico. Evolución, conceptos, componentes y clasificación. Visión gerencial, 10(1), 135-158.

Sancho, A. (Ed.) (1998). Introducción al Turismo. Organización Mundial del Turismo. Madrid.

Padt, F., Opdam, P., Polman, N. y Termeer, C. (2014). Scale-sensitive governance of the environment. Wiley-Blackwell.

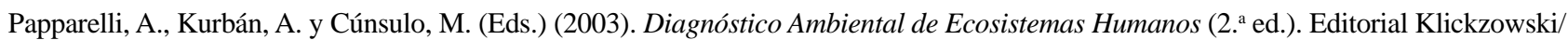
NOBUKO.

Podestá, M. M., Ré, A. y Romero, G. (2011). Visibilizando lo invisible. Grabados históricos como marcadores idiosincráticos en Ischigualasto. En L. Nuñez y A. E. Nielsen (Eds.), En ruta: arqueología, historia y etnografía del tráfico surandino (pp. 341-372). Encuentro Grupo Editor.

Rolandi, D. S., Guráieb, A. G., Podestá, M. M., Ré, A., Rotondaro, R. y Ramos, R. (2003). El patrimonio cultural en un área protegida de valor excepcional: Parque Provincial Ischigualasto (San Juan, Argentina). Relaciones de la Sociedad Argentina de Antropología, 28. Buenos Aires, Argentina.

Rolandi, D., Guráieb, A. G., Podestá, M. M., Re, A., Falchi, M. P., Rotondaro, R. y Torres, M. (2007). Investigación y gestión del patrimonio cultural en Ischigualasto (San Juan) y Palancho-Los Colorados (La Rioja) [VII Jornadas de Investigadores en Arqueología y Etnohistoria del centro oeste del país]. Río Cuarto, Córdoba. 
Rolandi, D. S., Podestá, M. M., Ré, A. y Falchi, M. P. (2008). El arriero en San Juan. Asociación Amigos del Instituto Nacional de Antropología.

Rotondaro, R., Ramos, R. A., Guráieb, A. G., Rolandi, D. S., Torres, M. A. y Podestá, M. M. (2007). Patrimonio Arquitectónico en Ischigualasto, San Juan, Argentina. Apuntes para su preservación e inclusión en los planes de turismo cultural. Anales del Instituto de Arte Americano e Investigaciones Estéticas Mario J. Buschiazzo, 87-111.

Santos-Pavón, E., Fernández-Tabales, A. y Muños-Yules, O. (2016). La incorporación del paisaje a la planificación turística. Análisis de la estrategia de turismo sostenible de Andalucía. Cuadernos de Turismo 37, 175-202.

Secretaría de Ambiente y Desarrollo Sustentable de la Nación. (2008). Estrategia de turismo sustentable en reservas de Biosfera y Sitios Ramsar de Argentina. PNUD Argentina.

World Tourism Organization (UNWTO). (2020). One planet vision for a responsible recovery of the tourism sector. https:// webunwto.s3.eu-west-1.amazonaws.com/s3fs-public/2020-06/one-planet-vision-responsible-recovery-of-the-tourism-sector.pdf

Yamila V. Andrada

Licenciada en turismo, egresada de la Universidad Nacional de San Juan (UNSJ). Becaria doctoral CONICET - UNSJ.

yami.v.andrada@gmail.com

ORCID: https://orcid.org/0000-0002-5103-7837

Pedro O. Narváez

Licenciado en Turismo. Especialista en Patrimonio Arqueológico de Paisajes Culturales de los Andes Meridionales. Profesor Titular Carrera de Licenciatura en Turismo de la Universidad Nacional de San Juan. Docente en la Diplomatura en Turismo Científico, UNSJ. Ex Presidente del Colegio de Profesionales en Turismo de la Provincia de San Juan (período 2012/2014).

enezeta@hotmail.com

ORCID: https://orcid.org/0000-0002-1272-7624

\section{Claudia M. Campos}

Bióloga, profesora de Biología y doctora en Ciencias Biológicas por la Universidad Nacional de Córdoba, Argentina. Es investigadora de CONICET. Trabaja en ecología de zonas áridas y relaciones entre la naturaleza y las personas.

ccampos@mendoza-conicet.gob.ar

ORCID: https://orcid.org/0000-0002-4978-5449 